\title{
A Local Approach Toward Multicultural Counseling in Malaysia
}

\author{
Nurul Syahida Mohd Ayob \\ Department of Counselor Education and Counseling Psychology \\ Faculty of Educational Studies, Universiti Putra Malaysia \\ 43400 UPM Serdang, Selangor, Malaysia
}

Siti Aishah Hassan (Corresponding author)

Department of Counselor Education and Counseling Psychology

Faculty of Educational Studies, Universiti Putra Malaysia

43400 UPM Serdang, Selangor, Malaysia

Mohd Hamdan Mohamed Nordin

Institute for Social Science Studies, Universiti Putra Malaysia

43400 UPM Serdang, Selangor, Malaysia

Received: Oct. 8, $2021 \quad$ Accepted: Nov. 8, $2021 \quad$ Online published: Nov. 25, 2021

doi:10.5296/ijhrs.v11i4S.19254 URL: https://doi.org/10.5296/ijhrs.v11i4S.19254

\begin{abstract}
Malaysia is a multicultural and multi-religious country. The importance of multicultural counseling has been widely recognized and discussed. Counselors need to be multiculturally-knowledgeable when dealing with multicultural clients. The effectiveness of counseling may likely be improved by integrating Malaysian approaches that are tailored to this country's traditions and insights, into the current conventional counseling practices. Most of these counseling and psychotherapy theories are based on, and biased towards, the Euro-American culture. Novice counselors in particular frequently reported a lack of skills in dealing with culturally-diverse clients. Multicultural counseling competency is an evolutionary progress that is meant to achieve an effective treatment, and greater inclusion of minorities in mainstream society. Therefore, this paper highlights multicultural counseling
\end{abstract}


competencies and the evolution of counseling in Malaysia. Using narrative method literature review, this paper presents local approaches toward counseling in Malaysia, based on various religions, which are specifically focused on an Islamic approach. This paper then compares and contrasts the local approaches with those of the conventional Western based counseling methods. Some recommendations that merit further investigation are highlighted for future studies.

Keywords: multicultural, multicultural counseling competency, counseling Malaysia, multi-religious country, novice counselors

\section{Introduction}

Currently, in the year 2021, Malaysia's population is estimated at 32.7 million with sex ratio is 106 males to every 100 females. Bumiputra is the majority with 69.8 percent of the population, followed, the Chinese population composition with 22.4 percent and while Indians and others are 6.8 percent. The composition of the population clearly shows Malaysia is a multicultural and multi-religious country. Therefore, understanding Malaysian culture and traditions is necessary for addressing multicultural counseling approaches (Mohan \& Sorooshian, 2012). Multicultural competency is an element that cannot be ignored by counselors if they have the intention to meet the needs of diverse client groups (Hassan \& Shuen, 2014). Being from a developed multicultural society, multicultural counseling training is necessary in most counseling education and training programs. It is pertinent to consider cultural norms for the effectiveness of the counseling service to be relevant to the intended population (Khoshbooii et al., 2021).

For future growth to take place, Mohan \& Sorooshian (2012) emphasized that counselors need to incorporate various therapeutic approaches into their practice techniques, such as multicultural approaches that give attention to religion, communities, and traditions from a Malaysian context. According to Hassan \& Shuen (2014), it is necessary to practice multicultural counseling in Malaysia, as Malaysia is a multicultural and multi-religious country. In fact, the importance of multicultural counseling has also been widely recognized and discussed (Ping \& Aga Mohd Jaladin, 2017). Hence, counselors need to be multiculturally competent when dealing with multicultural clients. As Malaysia aims to become a developed nation, Hassan (2015) stated that mental health issues are not necessarily similar to those observed amongst developed nations (Noor et al., 2014). Moreover, the Malaysian society is not yet familiar with the counseling concept, as most Malaysians still do not fully understand and are unaware of its importance, which may be based on the fear that they might be labeled as "Gila" (Mohan \& Sorooshian, 2012).

Therefore, the effectiveness of counseling should be improved by integrating Malaysian approaches that suit the needs of this country's traditions and insights, into that of the current conventional counseling practices. Most of the counseling and psychotherapy theories are based on, and biased towards, the Euro-American healing traditions (Hassan \& Shuen, 2014). Hassan and Shuen (2014) added that these theories are built around their values, which may not always be applicable and suitable for Malaysian clients, who are from different cultural traditions and believe in different religions such as Islam, Buddhism and Hinduism. 
In addition, Barden et al. (2014) also stated that novice counselors frequently reported a lack of skills in dealing with culturally diverse clients. Thus, one way for counselors to challenge and improve their current worldviews and assumptions would be culturally sensitive, by engaging in cultural immersion techniques, in order to develop multicultural counseling competencies. As stated by Ping \& Aga Mohd Jaladin (2017), multicultural counseling competencies is an evolutionary progress, which is meant to achieve an effective treatment, and much greater inclusion of minorities from the mainstream society.

A good introduction answers these questions in just a few pages and, by summarizing the relevant arguments and the past evidence, gives the reader a firm sense of what was done and why (Beck \& Sales, 2001, pp. 100-102).

\subsection{Objective of the Study}

The aim of this study is to highlight multicultural counseling competencies and the evolution of counseling in Malaysia. Accordingly, this paper presents local approaches toward counseling in Malaysia, based on various religions, which are specifically focused on an Islamic approach. This paper then compares and contrasts the local approaches with those of the Western based counseling methods.

\section{Method}

There are three basic forms of literature reviews, namely narrative reviews, qualitative systematic reviews, and quantitative systematic reviews. Narrative review is beneficial instructional papers since they condense a lot of information into a comprehensible style. It is useful for giving a general overview of a subject and frequently describes the history or development of a problem or its management (Green et al., 2006). Narrative review is frequently used as instructional papers to keep practitioners up to date and easier to read and more comprehensible as compared to systematic review. Therefore, this paper adopts narrative review and the sources listed in table 1 were used to gather information for this paper. Basically, the source of the literature gathered are from accessible UPM subscribed data based and open sources such as google scholar.

Table 1. Sources of literature used in this narrative review paper

\begin{tabular}{|l|l|}
\hline No & Sources \\
\hline 1 & Malaysian Journal of Medicine and Health Sciences. \\
\hline 2 & Journal of Multicultural Counseling and Development. \\
\hline 3 & Unpublished Doctoral Dissertation). Monash University, Melbourne, Victoria, Australia. \\
\hline 4 & Journal for International Counselor Education. \\
\hline 5 & The International Journal for the Psychology of Religion. \\
\hline 6 & Asian Social Science. \\
\hline 7 & Middle-East Journal of Scientific Research. \\
\hline
\end{tabular}




\begin{tabular}{|c|c|}
\hline 8 & Counseling and Values. \\
\hline 9 & International Journal of Business and Social Science. \\
\hline 10 & Australian Journal of Basic and Applied Sciences. \\
\hline 11 & Mental Health and Learning Disabilities Research and Practice. \\
\hline 12 & Malaysia Online Journal of Psychology \& Counselling. \\
\hline 13 & Journal of Black Studies. \\
\hline 14 & Journal of Counseling and Development. \\
\hline 15 & International journal of environmental research and public health. \\
\hline 16 & Social indicators research. \\
\hline 17 & International Journal for the Advancement of Counselling \\
\hline 18 & Journal for International Counselor Education \\
\hline 19 & Journal of Chiropractic Medicine \\
\hline 20 & Contemporary Issues in Malaysian Psychology \\
\hline 21 & Jurnal Psikologi Malaysia \\
\hline 22 & International Journal of Bilingual Education and Bilingualism \\
\hline 23 & Mental Health and Learning Disabilities Research and Practice \\
\hline 24 & Nursing times \\
\hline
\end{tabular}

\subsection{Multicultural Counseling Competency}

A multiculturally competent counselor as defined by Robinson \& Morris (2000), is a counselor who is aware, knowledgeable, and has the right skills in the areas of their own culture, as well as that of their clients. They are able to engage sensitively with clients who are culturally diverse, pertaining to the needs of their clients.

Sue et al. (1992) defined a multiculturally competent counselor as a counselor who participates actively in the process of becoming aware of his or her own assumptions about human behavior, values, biases, preconceived notions, personal limitations, and so on, and so forth. The counselor is also someone who is actively attempts to understand the worldviews of his or her culture differently across the clientele without negative judgments, as well as actively develops and practices appropriate, relevant, and sensitive intervention strategies and skills for working with his or her culturally different clients (Ping \& Aga Mohd Jaladin, 2017; Aga Mohd Jaladin, 2011). Barden et al. (2014) also added the development of multicultural counseling competencies which can be enhanced through exposure with people from different backgrounds, as it may help to develop cultural empathy, improve the individual's awareness, self-efficacy, and also their multicultural skills.

Therefore, in short, multicultural counseling competencies pertain to appropriate cultural awareness, knowledge, and skills, when dealing with culturally diverse clients (Hassan \& 
Shuen, 2014). According to Aga Mohd Jaladin (2011), Malaysian counselors appear to practice a systematic and culture-sensitive counseling basis when engaging with culturally different clients from a Malaysian context. However, there are some necessary qualities which are needed and reflects how a multiculturally competent counselor works (Aga Mohd Jaladin, 2011) such as (a) Background knowledge and experiences of the counselors, (b) Multicultural awareness, (c) Multicultural knowledge, (d) Multicultural understanding and (e) Multicultural skills.

\subsection{Evolution of Counseling in Malaysia}

According to Mohan \& Sorooshian (2012), guidance and counseling started in Malaysia through the work and leadership of the counseling profession in the United States, as it did across most of the world. $\mathrm{Ng}$ (2007) stated that counseling in Malaysia was established through the education systems, and addiction therapy, and counselors were placed into either school/university settings, or drug rehabilitation centers (Scorzelli, 1987).

Counselors are those who received formal training from recognized universities, and have a certified license from the Board of Counsellors under the 1998 Act. Ping \& Aga Mohd Jaladin (2017) added that there are three major differences amongst the governing ministries that help in coordinating the mental health-related services. The most well-known counseling association is the Persatuan Kaunseling Malaysia (PERKAMA).

The Lembaga Kaunselor Malaysia (LKM; 2011) code of ethics by PERKAMA is a set of guidelines for the profession, published by the Malaysia Board of Counsellors. Most employers in Malaysia require their counselors to be registered under LKM to comply with the Act 580 (Aga Mohd Jaladin, 2017).

The Department of Statistics Malaysia (2021) disclosed that a multicultural population of 32.75 million (including 3.01 million of noncitizens) along with the US Central Intelligence Agency's 2010 data, that 69.7\% were Malays, who were mainly Muslims (61.3\%); 22.5\% were Chinese, who were mainly Buddhists (19.8\%), Confucianism, Taiosts, and other traditional Chinese religions (1.3\%), with some were Christians (9.2\%); and $6.8 \%$ were Indians, who were mainly Hindus (6.3\%); while a small population were categorized as others (1.0\%) (Central Intelligence Agency, 2021). Bahasa Melayu is the first language in Malaysia, and English Language is the second language (Mohan \& Sorooshian, 2012). However, Malaysians tend to mix languages and dialects in daily conversations.

$\mathrm{Ng}$ (2007) stated that each culture in Malaysia has different roots, and has experienced cultural adaptations. For example, "bumiputera", is associated with the Malays and other indigenous groups such as the Iban, Kadazan and Bajau, while the Chinese and Indians were brought into Malaysia during the British colonization from Southern China and India, respectively. In addition, faith-beliefs have also been found to be associated with culture.Although the official religion in Malaysia is Islam, the Malaysia constitution does allow the freedom to practice other religions ( $\mathrm{Ng}, 2007)$.

There is an increasing alertness in integrating native Malaysian values with that of the Western counseling approaches (Ng, 2007). According to Smith (2003), Malaysian culture is 
already "hybrid" in nature, and all ethnic groups in this country have undergone a certain level of assimilation and toleration toward one another, which helps the society to live in harmony as a whole ( $\mathrm{Ng}, 2007)$. However, Mohan and Sorooshian (2012) said that the importance of counseling benefits should be further promoted across this society. Therefore, counselors in Malaysia need to have multicultural competence for providing professional services to a diverse population. Therefore, it is impossible to ignore the importance of multicultural counseling competence in a multicultural country like Malaysia (Ping \& Aga Mohd Jaladin, 2017).

The method section describes in detail how the study was conducted, including conceptual and operational definitions of the variables used in the study, as different types of studies will rely on different methodologies. However, a complete description of the methods used enables the reader to evaluate the appropriateness of the methods, and the reliability and the validity of the results. It also permits experienced investigators to replicate the study. If the manuscript is an update of an ongoing or earlier study, and the method has been published in detail elsewhere, one may refer the reader to that source, and simply give a brief synopsis of the method used in this section.

\subsection{Religion-Based}

Young et al. (2007) defined religion as "the specific organized and codified form through which individuals may express their spirituality". In terms of multiculturally competent practices, religion and/or spirituality is an often-neglected area (Scott et al., 2016). The authors stated that this needs to be reinforced by the individual, who noted that "counselors are less skilled in dealing with faith or religion as this area is often not a target of multicultural training". Thus, it is crucial for counselors to be aware and understand the religion, or spiritual aspect of their clients, so that they are prepared for all multicultural issues.

Currently, the largest religious group in the world are Christians. However, Muslims are expected to be equally large by 2050 (Mintert et al., 2020). Thus, as stated by Mintert et al., (2020), it is reported that clients often want to discuss the religious or spiritual aspects of their backgrounds while receiving therapy. Malaysia is unique in its diversity in religion, as religion is an important sociocultural value, and will always be a part of the life for each individual in Malaysia (Mohan \& Sorooshian, 2012). Typically: (a) Malays-Islam, (b) Chinese-Buddhism, (c) Indians-Hinduism, (d) Taoism, (e) Christians, (f) Aboriginal peoples and $(\mathrm{g})$ animism.

Based on $\mathrm{Ng}$ (2007), Malaysians are generally diverse regarding mental health views, and also for seeking alternatives. Most of the psychiatric patients in Malaysia first sought magico-religious treatments, before seeking professional care $(\mathrm{Ng}, 2007)$. Hence, although multicultural counseling is based on the universal principles of counseling psychology, it is very difficult for many counselors to practice without any recourse to that of religion (Hassan $\&$ Shuen, 2014).

\subsubsection{Islamic Counseling}


Based on the Islamic background in Malaysia, of which Muslims are the largest population in Malaysia at 61.3\% (Ping \& Aga Mohd Jaladin, 2017), some Islamic psychologists have started integrating Islamic perspectives into counseling practices (Haque \& Masuan, 2002).

$\mathrm{Ng}$ (2007) stated that, Dr. Azhar Md. Zain, a psychiatrist who is trained in the U.K on cognitive and behavioral therapy, returned to Malaysia in 1994, and proposed the use of cognitive and behavioral therapy in Malaysia. Later on, Azhar and other practitioners began integrating religious and sociocultural elements within the conventional approach, which produced good results. They received positive feedback for this religious-oriented psychotherapy from their patients, because it was in line with their values and identities. Since then, Islamic approaches showed significant growth in Malaysia (Haque \& Masuan 2002).

The Islamic perspective views on religion should not be forced onto people. Muslims do have the obligatory duty to spread the message of God regardless of backgrounds but Islam does not compel people to follow it (Hassan \& Shuen, 2014). Islamic counseling is based on Islamic perspectives of human nature, which integrates spirituality into the counseling process (Haque \& Masuan, 2002). This approach aims to focus on the underlying psychological needs from a religion-based perspective, which emphasizes spiritual approaches based on worshipping God, and the responsibilities as the servants of God.

\subsubsection{Measures and Covariates}

Include in the Method section information that provides definitions of all primary and secondary outcome measures and covariates, including measures collected but not included in this report. Describe the methods used to collect data (e.g., written questionnaires, interviews, observations) as well as methods used to enhance the quality of the measurements (e.g., the training and reliability of assessors or the use of multiple observations). Provide information on instruments used, including their psychometric and biometric properties and evidence of cultural validity.

\subsubsection{Human Nature}

Based on Hassan (2015), Langgulung (2001) explained that human nature is made up of two elements, namely, the physical (Jasd) elements, which are from the realm of creation ('alam al-khalq); and the spiritual (Ruh), which are from the realm of order ('alam al-amr). There is 'the soul' that connects the physical and the spiritual. The soul is further explained, and comes in three different forms (Qalb, Aql \& Nafs), as illustrated in Figure 1.

Based on the works of the past Muslims scholars, Langgulung (2001) explained the summarized meaning of the four concepts that constitute human consciousness (Hassan, 2015). "Nafs is the place of bad conduct, whereas Ruh is the source of life and the place of good conduct. Ruh is soft, pure and free from the influence of the Nafs. It came from Allah and its existence is unobservable; it is also the place of love and mercy, whereas the Qalb is the place of knowledge and the channels of perceptions. The Qalb cannot perceive unless it is free from the influence of the five senses. As for Aql, it is used for knowledge coming through the five senses using the thinking process. It is lower in rank than the Qalb. It is 
because both Nafs and Ruh attempt to drag the Qalb to its side, and the Qalb is sometimes influenced by the Ruh, and other times by the Nafs."

Therefore, he then ranked Nafs, Aql, Qalb and Ruh in ascending order, as shown in Figure 1. Accordingly, Hassan (2001) and Hassan et al. (2005) suggested that the dimensions of human nature can be philosophically viewed as a six-layer sphere. The spirit is the core of the sphere, which always remains pure. Then, it is followed by Qalb, which is considered an emotional dimension. Then, Aql has the intellectual dimension, followed by Nafs, the physiological dimension. This is then followed by Jasd, the physical, and Insan, the social dimensions of a human being, as the last layer. Figure 2 below demonstrates the six-layer sphere (Hassan, 2015).

According to Zakaria and Akhir (2017), some practitioners in Malaysia have applied Islamic theories and modules which have been formulated according to this country's society, such as (1) The Modification Model; a practice of conventional counseling through the implementation of Islamic teachings, and the exclusion of non-Islamic or non-Shariah compliances based on its interventions and strategies; (2) Integrative Models, through the integration of the conventional approaches, and traditional Islamic techniques, with both disciplines respecting original identities, and following scientific methods, including Islamic Cognitive Behavioral Therapy (iCBT), Cognitive al-Deen Counseling, and Spiritual Counseling (Kaunseling Bina Jiwa, KBJ); (3) Traditional Models which are meant as counseling approach based on the Quran, the Sunnah (the sayings, deeds and tacit approvals of Prophet Muhammad, PBUH) and literatures by Muslim scholars, such as Al-Ghazali's Models in counseling, Prophetic Style Counseling, and Asma Allah al-Husna Counseling Therapy.

Although the Muslim counselors have the obligatory duty to spread Islamic teachings, they also (counselors) need to maintain the global standard of professionalism associated with counselling (Hassan \& Shuen, 2014). Therefore, there should be no hindrance in counseling relationships for counselors and clients, regardless of religions and ideologies, because the focus of the assistance process should be along the goals of the counseling. However, it is undeniable that there are certain things which need to be well thought-out, as Islam is a religion with its own circumvented principles, and Muslims are meant to abide to it.

\subsection{Chinese and Others Local Approaches}

Chinese are the second largest group in Malaysia, and they are varied in their dialectic subculture, education background, generation, demography, and also degree of assimilation into the mainstream culture in Malaysia (Ting \& Foo, 2021). According to Ng (2007), the Chinese perspectives on mental health are also varied, as its heavily influenced by ancient Chinese philosophy, as well as animistic and folk religious beliefs (Haque, 2005). The Chinese philosophical views on good health are regulated by ch' $i$ (air or breath), which is a balance of physical, mental, and spiritual functions. The Chinese tend to reach out for help from Chinese physicians who use herbs, acupuncture, or ch'i-gong (a form of martial art) to re-balance the ch'i in their body. Haque (2005) added that situational expectations, especially in the family and society, are considered appropriate for an individual's well-being. When an 
individual is believed to be hysterically possessed by unwelcome spirits, $\mathrm{Ng}$ (2007) stated that the families usually seek help from their place of worship, or folk religious rituals, to get rid or appease the spirits.

Therefore, having a cultural sensitivity, awareness and knowledge towards different groups in the Chinese society in Malaysia is crucial toward becoming a competent counselor. Ting and Foo (2021) also stated that counselors should be trained with therapy skills, as there are specific issues which have been seen among Chinese in Malaysia, for example, (a) Cognitive-behavior therapy- The Chinese American community with its education and moralistic elements, and (b) A solution-focused approach- Chinese who prefer a practical approach, and quick solution.

In addition, having knowledge on the Chinese community's resources and traditional wisdom would be very helpful for the counselors when dealing with much more traditional Chinese, as many of them still practice folk religions like Taoists and ancestral worships (Ting \& Foo, 2021). Hence, knowing about these local practices as an added knowledge also can help improve cultural competency.Ting and Foo (2021) further elaborated that counselors also are encouraged to talk to different religious leaders in the Chinese community for wider exposure, as there are some Chinese practitioners who have started integrating religious approaches in their practices, such as Buddhist therapists using mindfulness and meditation, and Christian therapists using prayers and scriptures.

Studies also found that Malaysian counselors perceived multicultural counseling competencies which varied across the society, such as Malays, Chinese, and Indians. Among these three major ethnic groups in Malaysia, according to Aga Mohd Jaladin (2017), Indians showed a significant and positive interrelated correlation with the perceived multicultural counseling competencies. The author stated that this was consistent with the Holcomb-McCoy and Myers (1999) study, where the general perception on being a minority boosted the counselor's multicultural competence. Traditionally, Haque (2005) stated that Indians viewed mental health as being heavily influenced by Hinduism. According to the Vedas, they considered health as an integration of three elements: the body, mind, and soul. Mental health is related to diet (Haque, 2005). Similar to Buddhist philosophy, as some of the Indians may also be Buddhist, mental health is related to Karma, i.e., the fruit of one's actions, and also practicing the right mindset and delivering the right kind of action (Haque, 2005). Like the Chinese, Indians also usually seek help from their priests at Hindu temples $(\mathrm{Ng}$, 2007).

Generally, for non-Muslims, Christianity and Buddhism are the two major religions which have shaped the mental health views in Malaysia (Ng, 2007).

\subsection{Conventional Western Approach}

The conventional counseling models, such as psychoanalysis, behaviorism, humanism, and existentialism, have generally dominated the process of counseling. Hussein Rassool (2015) categorized these theories as (a) Directive counseling; Cognitive Behavior Therapy, Rational Emotive Behavioral Therapy, Gestalt, (b) Non-directive counseling, which is a Person 
Centered Therapy, (c) Eclectic counseling; the best/most suitable approach and technique from across different theories, that met the needs of the clients, (d) Integrative counseling, where, counselors combine elements from across different theories and models, and integrates them into a new model.

In terms of theoretical approaches in Malaysia, Mohamad and Ab Rahman (2011) stated that the Person-centered approach is the most widely used, followed by the Rational Emotive Behavioral Therapy (REBT), and the eclectic approach. Other theories seem to be less used, as they are not very suitable with the needs of the clients from a Malaysian context, as they may contradict with the client's religious principles (Mohamad \& Ab Rahman, 2011). The selection of these approaches have been identified to be influenced by several factors, such as (a) Religious backgrounds, (b) Family backgrounds, (c) Personality, and (d) Influence from former counselor educators.

According to Mohamad and Ab Rahman (2011), counseling services in Malaysia have increased gradually to both public and private sectors, which is in line with the increased awareness regarding mental health issues among Malaysians. From a Malaysian context, the early stages of counseling services are greatly influenced by the American style, where most of the lecturers obtained their training from institutions in the United States of America.

According to Aga Mohd Jaladin (2011), the general counselling process consists of three stages, which are before counseling, during counseling, and after counseling. Aga Mohd Jaladin (2011) provided a theoretical model on the mechanisms and processes involved when engaging with multicultural clients:

\section{The cross-cultural counseling processes}

In general, Malaysian counselors are found to focus on the pre-counseling stage, and cross-cultural relationship building, such as attending skills, and accepting clients unconditionally, which are meant as the critical stages for successfully engaging with clients from culturally different backgrounds. The theoretical model consists of three mechanisms and processes:

\section{a. Before counseling: making culturally appropriate preparations for counselling.}

Aga Mohd Jaladin (2011) suggested three (3) findings at this stage: the awareness and knowledge of counselors regarding their own cultures, as well as clients; the counselor's awareness of their own cultural background, the self-perceived attributes and competencies, and the counselor's awareness, basic knowledge, and understanding on culturally challenging issues, and the strategies to handle them with suitable multicultural approaches in Malaysia. All these essential elements may contribute to the effectiveness of multicultural counseling. Hence, counselors must develop these multicultural competencies as preparations, before engaging with issues related to culture and diversity.

\section{b. During counseling: engaging with culture and diversity}

This stage is characterized by the three general counseling processes; therapeutic cross-cultural relationship, multicultural case conceptualization, and culturally-appropriate 
interventions. In order to further describe this process, Aga Mohd Jaladin (2011) associated it with 4 necessary elements (i) Discussing the cultural differences in order to remain engaged, (ii) Using a culturally sensitive and appropriate framework when assessing the client's issues, (iii) Setting culturally appropriate counseling goals, and (iv) Developing a culturally sensitive and appropriate intervention.

The author emphasized that the most critical stage is where the counselor needs to be multiculturally competent when dealing with cultural differences that happen to exist between themselves and the clients, beforehand. Only then they can further continue with the relationship. Therefore, counselors need to be well-prepared with basic background knowledge and skills, and be able to think creatively when engaging with culturally challenging clients/issues.

\section{c. After counseling: evaluating the counseling outcomes}

Based on the findings, there are three crucial elements at this stage; the perceived progress across former clients, the counselor's level of satisfaction, and lessons learnt from the engagement experience (Aga Mohd Jaladin, 2011). Counselors usually expect that when there is a positive change, or progress observed in their former clients, then it reflects that the counseling was successful. The perceived progress that counselors usually attribute to the client's overall satisfaction are their readiness to change, self-acceptance, better self-understanding, awareness of their own feelings, and the willingness of following-up with the counselors. In addition, counselors are also encouraged to frequently assess their own counseling engagement by reflecting on their own satisfaction levels at the end of the relationship (Aga Mohd Jaladin, 2011).

Appropriate identification of research participants is critical toward the science and practice of psychology, particularly for generalizing the findings, making comparisons across replications, and using the evidence in research syntheses, and secondary data analyses. If humans participated in the study, it is important to report the eligibility and exclusion criteria, including any restrictions based on the demographic characteristics.

\subsection{Comparison of the Local Approaches the Conventional Western Approaches}

Counseling approaches in Malaysia are mostly taken from the Western models. Aga Mohd Jaladin (2017) discussed some comparative multicultural counseling competence frameworks between Malaysian and the Western world. A study conducted by Aga Mohd Jaladin (2017) revealed that the multicultural counseling competence of professional counselors in Malaysia consists of five aspects; multicultural understanding, multicultural knowledge, micro cultural skills, multicultural awareness, and macro cultural skills. This finding is consistent with the findings from Holcomb-McCoy and Myers (1999), which also found five aspects of multicultural counseling competence. However, there are some similarities and distinctions shared across both studies, which dealt with the cultural awareness, knowledge, and skill aspects found in both studies, which is summarized as shown in Table 2. 
Table 2. Differences of the approaches

\begin{tabular}{|c|c|c|}
\hline Differences & Local Approaches & Conventional Western Approach \\
\hline Theories & $\begin{array}{l}\text { Islamic Psychospiritual, Al-Ghazali } \\
\text { Counseling, Al-Balkhi } \\
\text { Psychotherapy, Cognitive Addin } \\
\text { Maqasid Shariah Discernment } \\
\text { Counseling, DHT Counseling }\end{array}$ & 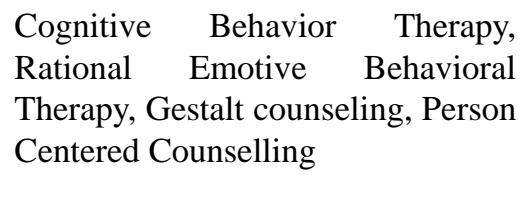 \\
\hline We vs I & $\begin{array}{l}\text { Use "we" indicating value for } \\
\text { collectivism. } \\
\text { valuing a harmonious relationship, } \\
\text { the importance of face-saving, and } \\
\text { religious orientation. }\end{array}$ & $\begin{array}{l}\text { Use "I" indicating value of } \\
\text { individualism }\end{array}$ \\
\hline Family vs Individual & $\begin{array}{l}\text { Malaysian consider families as an } \\
\text { important resource, however, most } \\
\text { of the counseling training in } \\
\text { Malaysia have focused on } \\
\text { individual-based sentiments, with } \\
\text { minimal weight on family } \\
\text { structures. }\end{array}$ & $\begin{array}{l}\text { Systemic Family Counseling/ } \\
\text { Therapy emphasis on involvement } \\
\text { of family members in the counseling } \\
\text { sessions }\end{array}$ \\
\hline $\begin{array}{l}\text { Family \& friend vs } \\
\text { professional helps }\end{array}$ & $\begin{array}{l}\text { Clients need to gain the confidence } \\
\text { and trust first, before seeking } \\
\text { counseling to talk about the } \\
\text { confidential aspects of one's life, } \\
\text { which is very much valued. } \\
\text { They preferred someone they know } \\
\text { instead of total stranger }\end{array}$ & $\begin{array}{l}\text { Professional help seeking is valued } \\
\text { instead of family and friends }\end{array}$ \\
\hline $\begin{array}{l}\text { Cultural Differences on "self- } \\
\text { disclosure" }\end{array}$ & $\begin{array}{l}\text { shame, and face-saving reactions } \\
\text { for self-disclosure especially related } \\
\text { to family matters }\end{array}$ & $\begin{array}{l}\text { sell-disclosure is considered as } \\
\text { effective techniques }\end{array}$ \\
\hline
\end{tabular}

Having a much better understanding of Malaysian culture can be obtained by looking deeper at its culture, values, and norms (Mohan \& Sorooshian, 2012). Mohan and Sorooshian (2012) further explained that Malaysian values are deep-rooted and different from the Western one, for example, respecting, more emphasis more on 'we' than 'I', valuing a harmonious relationship, the importance of face-saving, and religious orientation. Whereas, from an international perspective, Manery (2000) said that some values which differentiate Malaysians with that of the Western culture are the importance of the extended family, shame, and face-saving reactions, pressure for academic achievement, authoritarianism, and men as being the head of the family. Hassan and Shuen (2014) also added that among the main values of Euro- Americans is the aspect of individualism. In short, the most important dimension is individualism versus collectivism (Mohan \& Sorooshian, 2012).

In addition, the Malaysian society needs to gain the confidence and trust first, before seeking counseling to talk about the confidential aspects of one's life, which is very much valued (Mohan \& Sorooshian, 2012). Self-disclosure of one's personal issues are a reflection of both the individual's life and their family structure. Thus, most families place a strong emphasis on 
exercising privacy. Despite the fact that Malaysian people consider families as an important resource, however according to $\mathrm{Ng}$ (2007), most of the counseling training in Malaysia have focused on individual-based sentiments, with minimal weight on family structures. It was only recently that family counseling was integrated into the curriculum. The emphasis on face-saving could be a factor that contributes to this norm ( $\mathrm{Ng}, 2007)$. In the Western society, being assertive is much more encouraged. Malaysian people value respect, and by being too assertive, it might not be appropriate in a Malaysian context. (Mohan \& Sorooshian , 2012)

\section{Recommendation}

Various approaches can be seen to have been used by counselors to provide counseling to those in need (Mohamad \& Ab Rahman, 2011). Examples given by Mohan and Sorooshian (2012) showed a lack of self-awareness, insight, and feelings, and behavioral problems. These issues can be managed with appropriate suitable techniques and approaches, where many have taken lightly the importance of counseling in managing one's common daily life issues.

Counseling plays a vital role in lives, where it can provide professional help with the use of different counseling approaches, such that it is deemed suitable to address the concerns of the clients. From a Malaysian context, Mohan and Sorooshian (2012) stated that Malaysians are still doubtful or unaware about counseling, which has hindered them from seeking aid. In many cases, face-saving has been the primary factor, due to the social stigma that still prevails within Malaysian society, regarding mental health issues. Hence, as suggested by Aga Mohd Jaladin (2011), to develop much more meaningful counseling relevance from a Malaysian context, it is crucial for the counselors to use approaches which are suitable with the values and needs of the Malaysian people. This brings us to the basic characteristics of how to be a multiculturally competent counselor, as previously explained by Aga Mohd Jaladin (2011). Counseling courses and training programs should be designed by integrating all five components of multicultural competence for counselors to nurture in-depth multicultural counseling programs (Aga Mohd Jaladin, 2017). Possibly, the novices could be the first to be familiarized to the five fundamental elements of being multiculturally competent counselors.

It is certain that counseling courses and training from a Malaysian context are very significant in fostering counselors to become multiculturally competent (Aga Mohd Jaladin, 2011). For instance, pre-service counselors have to possess basic knowledge on Malaysian cultures, and reflect on the meaning of these cultures from within their own cultural selves. This benefits the novices in increasing their own awareness on cultural identity of themselves and their clients, and become much more knowledgeable to recognize issues that arise from a specific cultural context, and become much more skillful in dealing with such issues from a counseling context. Whereas, for active counselors, they should have more opportunities to join professional development training, such as additional training programs on the understanding and practice of multicultural counseling, as it helps to expand their skills when dealing with clients that are culturally different. The participation in such training programs can improve the counselor's multicultural competencies (Aga Mohd Jaladin, 2011). 
Another area of concern according to $\mathrm{Ng}$ (2007) had to do with language barriers. He further elaborated that circumstantial information showed that to find therapists for non-Malay or non-English speakers is somehow difficult. Therefore, counselors who are able to communicate across multi-languages are greatly in demand. Hence, multilingual abilities can be emphasised as a criteria when selecting counseling graduates, as well as in the curriculum pertaining to counselors training $(\mathrm{Ng}, 2007)$. This certainly will have an implication in becoming a competent multicultural counselor.

Ping and Aga Mohd Jaladin (2017) noted that in Malaysia, there is not much cultural and social mixing in counseling agencies, which creates an environment where counselors do not get to work with culturally diverse clients, due to the categorization of counseling agencies based on specific languages and religions. This has caused counselors difficulty in improving their multicultural skills. As stressed by Ping and Aga Mohd Jaladin (2017), practical experience is essential for counselors to learn from. Therefore, integrating the practical approach into the current syllabus of theory-based counseling programs should be enhanced much more, for example, from site visits, culturally-related programs, individuals, and group counseling with culturally different clients, to gain first-hand experiences, for example, on culturally sensitive issues, such as religion, sexuality, and the LGBT community, to ultimately enable students to become better counselors pertaining to multicultural competencies (Ping \& Aga Mohd Jaladin, 2017)

In addition to that, Barden et al. (2014) suggested that cultural immersion programs can be one of the opportunities provided to counselors as a form of their first-hand experiences, for witnessing the challenges faced by the minorities, identifying the relationship of culture with one's behavior, and the importance for counselors to be culturally sensitive. This was also supported by Aga Mohd Jaladin (2017), as counseling courses and training programs should highlight the real-world elements in the curriculum, to better educate and train counselors. Exposing students to the diversity of cultural languages and traditions during immersions help to boost multicultural skills, and the self-efficacy needed for novices to be much more appropriately suited to assess cultural differences (Barden et al., 2014). Likewise et al. (2013) added that the most critical experience of the immersion phase is to engage in counseling related activities, such as conducting group counseling, working in schools with students, and doing art therapy at domestic violence shelters with community members.

\section{Conclusion}

In conclusion, counselors in Malaysia generally already possess an adequate idea of multicultural counseling, where most of the counselors are already aware, knowledgeable, and are able to identify the socio-cultural background of the client's beliefs and values. Counselors in Malaysia mostly viewed themselves to be multiculturally competent. They viewed themselves to be mostly competent in multicultural knowledge, and understanding various such aspects. They were found to be least competent in multicultural awareness and associated skills. This is in contrast with the findings among the US counselors, who viewed themselves to be most competent on multicultural awareness aspects, and the least competent on the knowledge aspect. 
Malaysian counselors perceived multicultural counseling competence as being varied by culture, education background, and training. Indians, compared to other major cultural groups in Malaysia, showed a significant and positive interrelated correlation with the perceived multicultural counseling competency. This finding was consistent with Western cultural findings, where the general perception on being a minority boosts the counselor's multicultural competence. In short, the overall finding showed a connection between ethnic groups and multicultural counseling competencies, and between the counselor's professional education, development training, and multicultural counseling competencies. Through such understanding, counselors are expected to be able to handle multicultural issues such as racism, prejudice, discrimination, stereotyping and ethnocentrism, much better. Therefore, it is important for counselors to have creativity in the adaptation of skills, knowledge, and techniques learnt, in order to contribute toward the sensitivity, efficiency, and effectiveness of counseling services provided.

\section{References}

Aga, M. J. R. (2017). Perceived multicultural counseling competence of Malaysian counselors: An exploratory study. Journal of Multicultural Counseling and Development, 45(2), 127-148.

Aga, M. J. R. (2011). How to successfully engage with culture and diversity issues in a cross-cultural counselling process: From research to better practice. Unpublished Doctoral Dissertation). Monash University, Melbourne, Victoria, Australia.

Barden, S. M., \& Cashwell, C. S. (2013). Critical factors in cultural immersion: A synthesis of relevant literature. International Journal for the Advancement of Counselling, 35(4), 286-297. https://doi.org/10.1007/s10447-013-9183-y

Barden, S. M., Mobley, K., \& Shannonhouse, L. (2014). Cultural immersion in counselor education in the United States: A quasi experimental study. Journal for International Counselor Education, 6(1), 3.

Central Intelligence Agency. (2021). Central Intelligence Agency. https://www.cia.gov/the-world-factbook/countries/malaysia/.

Department of Statistics Malaysia Official Portal. (2021). Demographic Statistics First Quarter 2021, Malaysia. https://www.dosm.gov.my/v1/index.php?r=column\%2FcthemeByCat\&cat=430\&bul_id=aVlJ RDAvbjhWWEhQa1YvSWhsSjF3QT09\&menu_id=L0pheU43NWJwRWVSZklWdzQ4TlhU UT09.

Green, B. N., Johnson, C. D., \& Adams, A. (2006). Writing narrative literature reviews for peer-reviewed journals: secrets of the trade. Journal of Chiropractic Medicine, 5(3), 101-117. https://doi.org/10.1016/s0899-3467(07)60142-6

Haque, A. (2005). Mental health in Malaysia: An overview. In Ansari, Z.A., Noor, N.M. \& Haque, A. (Eds.). Contemporary Issues in Malaysian Psychology. Singapore: Thomson Learning. 
Haque, A., \& Masuan, K. A. (2002). Religious psychology in Malaysia. The International Journal for the Psychology of Religion, 12, 277-289. https://doi.org/10.1207/S15327582IJPR1204_05

Hassan, S. A. (2015). Islamic transcendental wellbeing model for Malaysian Muslim women: Implication on counseling. Asian Social Science, 11(21), 331. https://doi.org/10.5539/ass.v11n21p331

Hassan, S. A., \& Shuen, P. K. (2014). An Islamic perspective on multicultural counseling: A Malaysian experience of Triad Training Model (TTM). Middle-East Journal of Scientific Research, 19, 54-60.

Hassan, S. A., Abdullah, A. S., Langgulung, H., \& Ishak, N. (2005). Fostering Mother-Child Relationship via Creator-Creature Relationship: A Structural Equation Modelling Analysis. Jurnal Psikologi Malaysia, 19, 69-82.

Malaysia, L. K. (2011). Piawaian dan kelayakan latihan kaunselor Lembaga Kaunselor (Malaysia). Kuala Lumpur: Penerbitan Lembaga Kaunselor Malaysia.

Holcomb-McCoy, C. C., \& Myers, J. E. (1999). Multicultural competence and counselor training: A national survey. Journal of Counseling \& Development, 77(3), 294-302. https://doi.org/10.1002/j.1556-6676.1999.tb02452.x

Manery, G., (2000). Theraplay with Asian-Canadian families: Practical and theoretical considerations. [Online] Available: http://www.theraplay.org/articles/sum00_pg2.html (10th May, 2009).

Mintert, J., Tran, A. G., \& Kurpius, S. (2020). Religious and/or spiritual social justice advocacy: Guidance from the multicultural and social justice counseling competencies. Counseling and Values, 65(1), 2-14. https://doi.org/10.1002/cvj.12119

Mohamad, Z., \& Ab Rahman, A. H. (2011). Counseling practitioners in Malaysia: Socio-demographic profile and theoretical approaches in counseling process. International Journal of Business and Social Science, 2(22).

Mohan, S. B. V. R., \& Sorooshian, S. (2012). Counseling in the context of Malaysian living style. Australian Journal of Basic and Applied Sciences, 6(10), 292-296.

Noor, N. M., Gandhi, A. D., Ishak, I., \& Wok, S. (2014). Development of indicators for family well-being in Malaysia. Social Indicators Research, 115(1), 279-318. https://doi.org/10.1007/s11205-012-0219-1

Ng, W. S. (2007). Psychotherapy in Malaysia-an overview. Mental Health and Learning $\begin{array}{llll}\text { Disabilities Research } \quad \text { and 205-217. } & \text { Practice, }\end{array}$ https://doi.org/10.5920/mhldrp.2007.42206

Ping, V. S. \& Aga Mohd Jaladin, R. (2017). The Relationship Between Malaysian Counselors' Multicultural Counseling Competence and Client Satisfaction. MOJPC: Malaysia Online Journal of Psychology \& Counselling, 1(1). 


\section{Macrothink}

International Journal of Human Resource Studies ISSN 2162-3058 2021, Vol. 11, No. 4S

Rassool, G. H. (2015). Cultural competence in nursing Muslim patients. Nursing Times, 111(14), 12-15.

Ratts, M. J., Singh, A. A., Nassar-McMillan, S., Butler, S. K., \& McCullough, J. R. (2015). Multicultural and social justice counseling competencies. https://doi.org/10.1002/jmcd.12035

Robinson, D. T., \& Morris, J. R. (2000). Multicultural counselling: Historical context and current training consideration. Journal of Black Studies, 24(4), 239-253.

Scott, S. K., Sheperis, D. S., Simmons, R. T., Rush-Wilson, T., \& Milo, L. A. (2016). Faith as a cultural variable: Implications for counselor training. Counseling and Values, 61, 192-205. https://doi.org/10.1002/cvj.12037

Sue, D. W., Arredondo, P., \& McDavis, R. J. (1992). Multicultural counseling competencies and standards: a call to the profession [conceptual paper]. Journal of Counseling and Development, 70, 477-486. https://doi.org/10.1002/j.1556-6676.1992.tb01642.x

Scorzelli, J. F. (1987). Drug Abuse in Southeast Asia.

Smith, K. J. (2003). Minority language education in Malaysia: Four ethnic communities' experiences. International Journal of Bilingual Education and Bilingualism, 6, 52-65. https://doi.org/10.1080/13670050308667772

Ting, R. S. K., \& Foo, P. L. (2021). Counseling Chinese communities in Malaysia: The challenges and needs in mental health service deliverance. In Research Anthology on Rehabilitation Practices and Therapy (pp. 1175-1201). IGI Global. https://doi.org/10.4018/978-1-7998-3432-8.ch058

Tomlinson-Clarke, S. M., \& Clarke, D. (2010). Culturally focused community-centered service learning: An international cultural immersion experience. Journal of Multicultural $\begin{array}{lllll}\text { Counseling } \quad \& \quad \text { Development, } & 38,\end{array}$ https://doi.org/10.1002/j.2161-1912.2010.tb00124.x

Young, J. S., Wiggins-Frame, M., \& Cashwell, C. S. (2007). Spirituality and counselor competence: A national survey of American Counseling Association members. Journal of Counseling \& Development, 85, 47-52. https://doi.org/10.1002/j.1556-6678.2007.tb00443.x

Yusoff, S., Hassan, S., Norhayati, W., \& Othman, W. (2019). Traditional and Complementary Treatments among Malay, Chinese and Indian Chronic Diseases: A Systematic Review. Malaysian Journal of Medicine and Health Sciences, 15(SUPP1), 2636-9346. https://core.ac.uk/download/pdf/219504024.pdf

Green, B. N., Johnson, C. D., \& Adams, A. (2006). Writing narrative literature reviews for peer-reviewed journals: secrets of the trade. Journal of Chiropractic Medicine, 5(3), 101-117. https://doi.org/10.1016/S0899-3467(07)60142-6

Khoshbooii, R., Hassan, S. A., Deylami, N., Muhamad, R., Engku, K. E. M., \& Alareqe, N. A. (2021). Effects of Group and Individual Culturally Adapted Cognitive Behavioral Therapy on Depression and Sexual Satisfaction among Perimenopausal Women. International Journal of 


\section{Macrothink}

International Journal of Human Resource Studies ISSN 2162-3058 2021, Vol. 11, No. 4S

$\begin{array}{lllll}\text { Environmental Research } \quad \text { and Public Health, } & \text { 18(14), }\end{array}$ https://doi.org/10.3390/ijerph18147711

\section{Appendix A}

The Heading to Appendix A

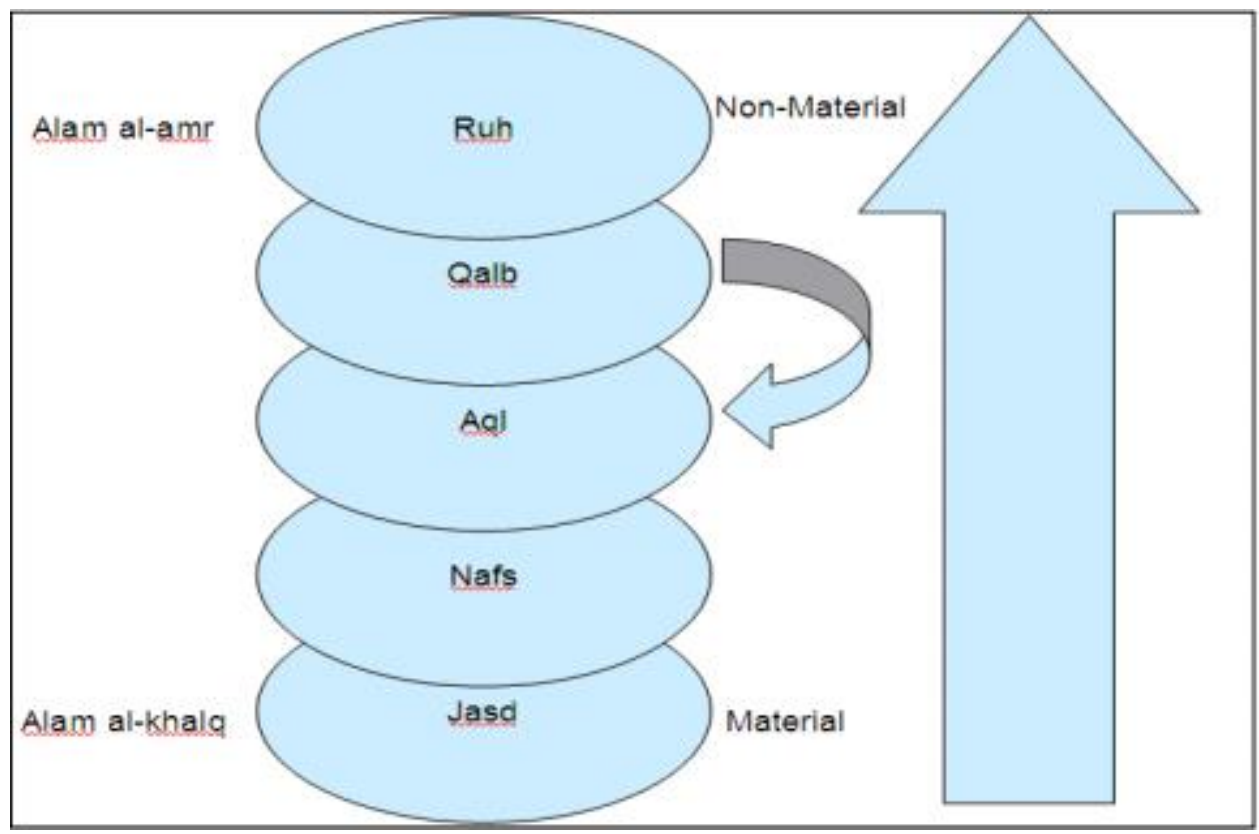

Figure 1: Human Consciousness

Source : Hassan, (2015). 


\section{Macrothink Institute $^{\mathrm{TM}}$}

\section{Appendix B}

The Heading to Appendix B

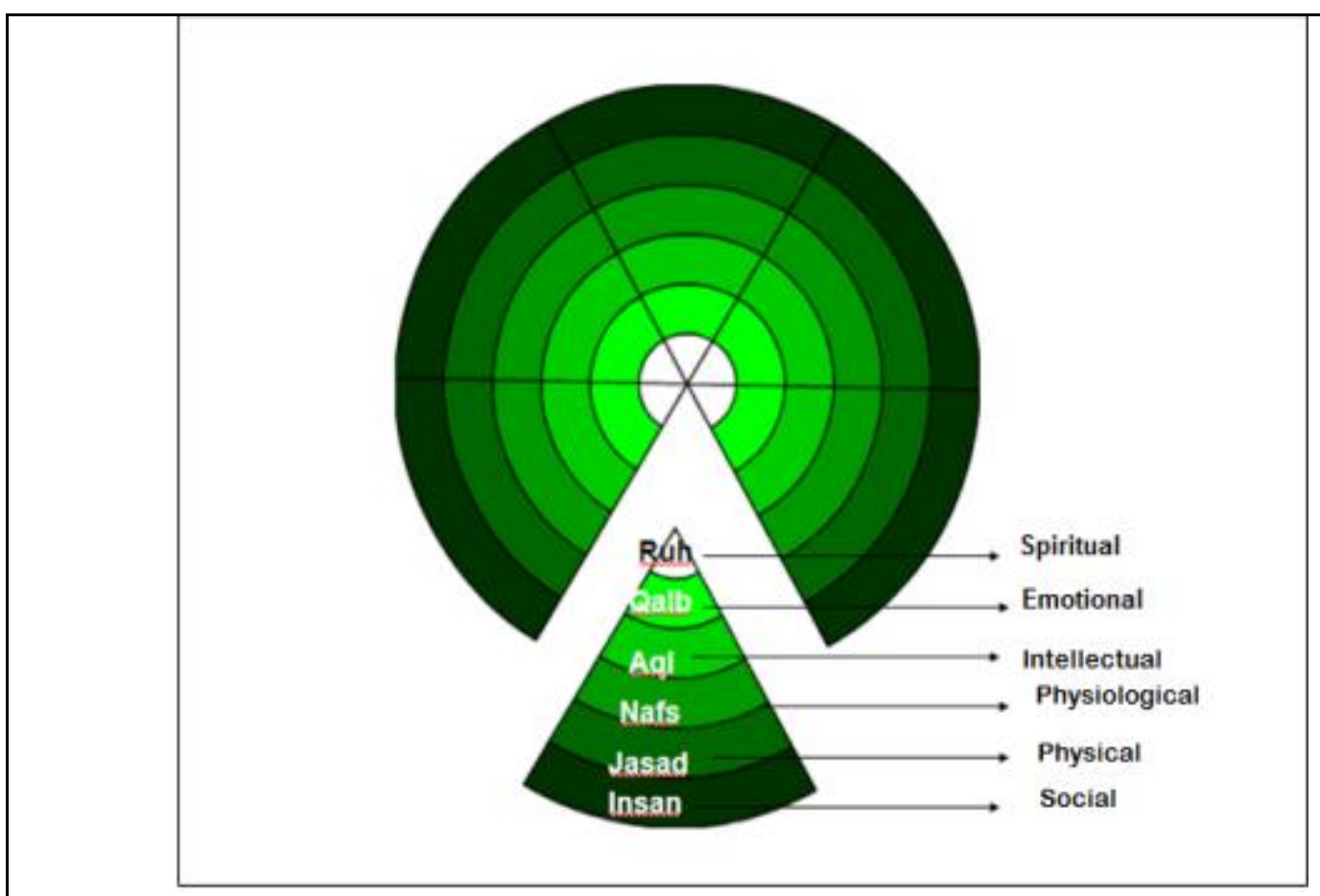

Figure 2: Dimensions of Human Nature,

Source : Hassan, (2015). 


\section{Appendix C}

\section{The Heading to Appendix C}

Figure 3: Theoretical model for engagement process with culturally different clients described by counsellors.

Source: Aga Mohd Jaladin (2011)

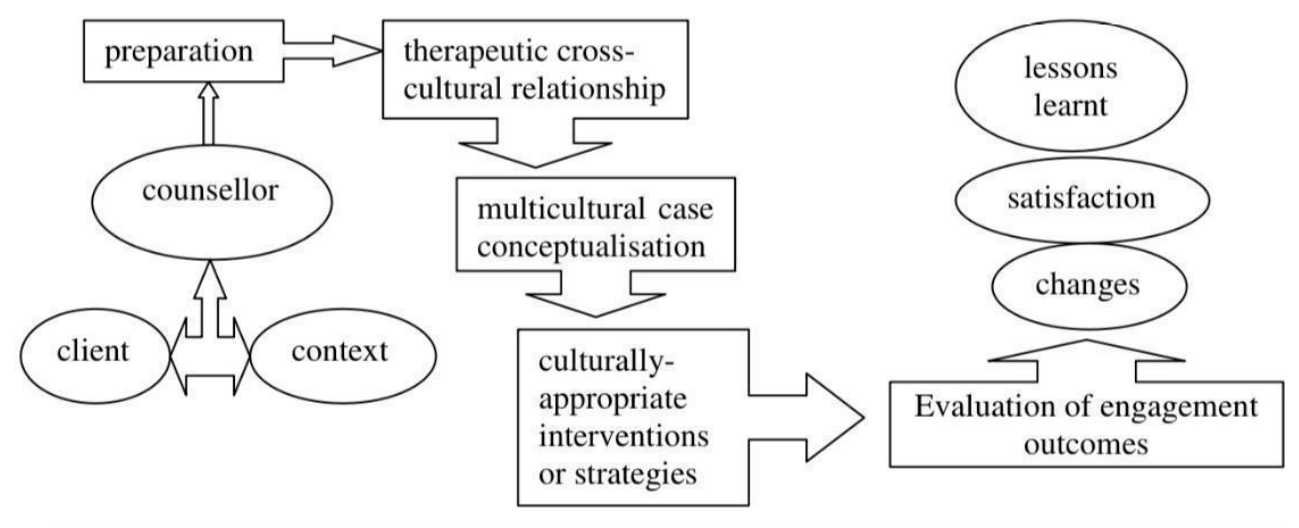

Mechanisms:

Awareness, beliefs and attitudes, knowledge, understanding, experience, skills

\begin{tabular}{|c|c|c|}
\hline PRE-COUNSELLING & ENGAGING WITH CULTURE & POST-COUNSELLING \\
\hline
\end{tabular}

\section{Copyright Disclaimer}

Copyright for this article is retained by the author(s), with first publication rights granted to the journal.

This is an open-access article distributed under the terms and conditions of the Creative Commons Attribution license (http://creativecommons.org/licenses/by/4.0/). 